\title{
Assessment of Irrigation Pricing Policies: A Data Envelopment Analysis Approach
}

\author{
Giacomo Giannoccaro ${ }^{1}$, Maurizio Prosperi ${ }^{1}$, Francisco Alcón $^{2} \&$ Julia Martin-Ortega ${ }^{3}$ \\ ${ }^{1}$ Dpt. SAFE, University of Foggia, Foggia, Italy \\ ${ }^{2}$ Dpt. Economía de la Empresa-Área de Economía, Sociología y Política Agraria. Universidad Politécnica de \\ Cartagena, Cartagena, Spain \\ ${ }^{3}$ Social, Economic and Geographical Sciences, The James Hutton Institute, Aberdeen, Scotland UK \\ Correspondence: Giacomo Giannoccaro, Dpt. SAFE, University of Foggia, Via Napoli, 25-Foggia 71100, Italy. \\ E-mail: g.giannoccaro@unifg.it
}

Received: March 8, 2013 Accepted: April 20, 2013 Online Published: April 25, 2013

doi:10.5539/enrr.v3n3p10 URL: http://dx.doi.org/10.5539/enrr.v3n3p10

\begin{abstract}
The European Water Framework Directive encourages pricing policy reforms in order to protect the environmental quality of water and promote its efficient use. This paper deals with two aspects of efficiency, namely economic and environmental efficiency, analyzed for different pricing methods. Volumetric pricing methods are compared with other indirect schemes ('per area', on 'input', on 'output' and 'quota') under three different water saving scenarios. The Data Envelopment Analysis (DEA) technique is used to assess the eco-efficiency of an eventual water pricing reform in the irrigated agricultural system of Capitanata, in Italy. Overall, findings point out that a pricing system based on 'per area' and 'output' will lead to the highest eco-efficiency, although this is not valid under any water pricing charge. The enforcement of water saving via pricing does not imply a higher eco-efficiency, mainly in the case of environmental efficiency. The use of the DEA approach appears useful in the assessment of water pricing policies where conflictive economic and environmental goals arise. It provides a methodology to support policy makers in the design of water policy pricing aimed at the enhancement of efficiency, both economic and environmental.
\end{abstract}

Keywords: eco-efficiency, data envelopment analysis, water pricing scheme, irrigation

\section{Introduction}

The enhancement of water use efficiency is one of the priorities of the European Water Framework Directive (WFD), which sets the target of achieving a sustainable use of water that guarantees the good ecological status of all water bodies. The most relevant impact from its implementation is expected on the agricultural sector, since it accounts for $60-80 \%$ of the overall demand (Dworak et al., 2007). To achieve its objectives, the WFD prescribes the use of economic tools and principles, such as the full cost recovery of water services, and the polluter pays principle (Martin-Ortega, 2012).

In this regard, a water-pricing reform would (directly or indirectly) "[ . . ] provide adequate incentives for users to use water resources efficiently, and thereby contribute to the environmental objectives of this directive", as stated by Article 9 of the WFD. This paper is aimed at providing scientific support to the implementation of the WFD in this respect, by assessing the efficiency of several water pricing policies for irrigation. The volumetric pricing is commonly believed to be more effective because payments are directly linked to actual delivered water (Dono, Giraldo, \& Severini, 2010). However, its implementation is hindered by some technical difficulties, such as the application of metering devices to different kinds of water sources (streams, natural reservoirs, groundwater, wells, etc.); and their monitoring and surveillance (Molle \& Berkoff, 2007). Moreover, volumetric systems are costly and, as it is pointed out by Tsur and Dinar (1997), in some areas the efficiency gains may not be sufficient to cover the costs for water pricing reform. This paper tries to address the research question of whether alternative pricing schemes may also be suitable (or eventually better) for the achievement of WFD's environmental objectives in accordance with its economic efficiency principles.

The main added value of this research relates to the joint assessment of economic and environmental efficiency. Economic efficiency relates to the adequate allocation of the water resource among different irrigated crops, and 
its capacity to generate economic outputs. Environmental efficiency relates to the capacity of pricing schemes to reduce externalities caused by irrigated agriculture on the environment. These two concepts, when considered together, yield the measure of eco-efficiency. The assessment is performed by simultaneously considering technical input, negative environmental externality (i.e. undesirable) and economic outputs (i.e. desirable) (Färe, Grosskopf, Lovell, \& Pasurka, 1989; Titeca, 1996; Kuosmanen \& Kortelainen, 2005; Picazo-Tadeo, Gómez-Limóm \& Reig-Martínez, 2011). This approach represents a contribution to the literature since at present, most studies concerning water productive efficiency follows an agronomic approach (yield per drop) or an engineering approach (conveyed water per available water) (see Malano \& Burton, 2001) for a comprehensive list of the water efficiency indicators) and do not look at eco-efficiency as a measurement of global performance of irrigated agriculture, ignoring the fact that conflicting economic and environmental objectives may emerge.

Particular focus is placed here on insights into the improvement of eco-efficiency stemming from a water policy reform in agriculture adopting a macro-level perspective. More specifically, eco-efficiency is defined here as the ratio between economic value added and some indicators of environmental pressures such as nitrogen balance and risk of pesticides. The analysis is carried out at regional scale for the agricultural system as a whole. The study refers to the catchment of the irrigation basin named 'Consorzio della Bonifica della Capitanata' (CBC), which is located in the province of Foggia (Apulia region), Italy. Results are, nevertheless, expected to be of relevance at the wider level in Europe, where other water scarce regions face similar water management issues.

To address the research objectives, the overall effects of alternative hypothetical water pricing schemes are firstly simulated by a regional linear programming model (LP). Then, the assessment of the eco-efficiency is undertaken through a Data Envelopment Analysis (DEA). The use of simulated date to feed into DEA has already proven appropriate by the literature (e.g., Musolino \& Rindone, 2009; Bono \& Matranga, 2005). Raju and Kumar (2006) used DEA to select the most suitable irrigation planning alternative in the context of the Sri Ram Sagar Project in Andhra Pradesh (India). In this research, simulated data allows avoiding the interferences on the efficiency due to other external factors. As consequence, efficiency gains are more clearly related to the water policy change.

This combination of LP and DEA represents another added value of this research. Simply using the LP model outputs and accounting for the implied changes due to different pricing policies goes into largely argued problems of multi-input/multi-output production processes evaluation (Gómez-Limón \& Sanchez-Fernandez, 2010). Indeed, inputs, outputs, and externalities can be measured in physical or value terms, but the most difficult task is the comparison of different performances. The greatest difficulty involves interpreting the combination of indicators selected to describe each policy effect, and therefore to be suitable as a practical administrative decision-support tool (Messner, 2006). Instead, DEA technique is expected to overcome the usual trade-off amongst the conflicting objectives as economic and environmental, as well as the possible commensurability and aggregation biases of different indicators.

The structure of this paper is as follows. Section 2 reports the main topics of water pricing policy options. Section 3 follows, where the empirical case and alternative pricing schemes are compared. Section 4, presents the methodology based on the two-stage DEA approach. Results are presented in Section 5 while conclusions are drawn in Section 6.

\section{The Water Pricing Policies}

It has been stated that the most suitable water pricing scheme to encourage users to limit their water is one based on volumetric billing use (Easter \& Liu, 2005). The shortcomings of a volumetric approach have also been discussed in literature. For instance, Dono, Giraldo, and Severini (2010) analyze the economics effects and impacts of water usage of a volumetric approach with respect to an area based method. They point out that charge increases via volumetric schemes could stimulate groundwater withdrawal. Generally, criticisms of the volumetric methods for water irrigation management in semi-arid regions and other relevant water pricing methods have been argued (Viaggi, Raggi, Bartolini, \& Gallerani, 2010; Molle, Venot, \& Hassan, 2008). In addition, it has been largely recognized that the implemantation of direct methods in large irrigation districts implies the adoption of appropriate water metering devices, which in turn may require massive investment for their setting and monitoring (Molle \& Berkoff, 2007; Burt, 2007).

There are many papers dealing with water pricing for irrigation and efficiency issue (Tsur \& Dinar, 1995; Dinar \& Subramanian, 1997; Johansson, Tsur, Roe, Doukkali, \& Dinar, 2002). Basically, they show that the gain in efficiency is often not prevalent with respect to the implementation costs and obstacles related to volumetric pricing implementation (Tsur \& Dinar, 1997).

While research focusing on economic issues, often at farm level, are largely available (e.g. Bazzani, Di Pasquale, 
Gallerani, \& Viaggi, 2004; Ortega, de Juan, \& Tarjuelo, 2004; Speelman et al., 2009), how volumetric pricing affects the environmental efficiency of irrigation systems have received less attention. Important contributions have been made by some authors in the field of policy analysis towards non-point source control in irrigated agriculture. Most of these papers refer to the cost and environmental effectiveness of measures such as eco-tax, permits trading, land use restrictions, nitrate pollution reduction at the farm (O'Shea \& Wade, 2009) or at regional level (Martínez \& Albiac, 2004; Volk, Lierscha, \& Schmidt, 2009). However, most of the mentioned studies, which focus on farm impacts, are crop specific and none of these explicitly tackle the eco-efficiency of water use as a consequence of water pricing changes.

Moreover, there is the issue of whether alternative pricing schemes might perform better than volumetric billing when both economic and environmental efficiency are considered. To address this research gap, six water pricing schemes are compared here. Simple volumetric schemes and increasing block tariffs are the direct systems, whereas the indirect pricing schemes are area, input, output and quota pricing:

a) Volumetric schemes are based on the amount of water delivered. The price should be set equal to the marginal cost (i.e. financial, environmental and, resources costs) of providing the water from the economic optimal pricing rule. This pricing method, easily understood, leads farmers to use water efficiently until the economic marginal value equals the marginal cost. The main disadvantage of this method is that it requires meters and it has considerable implementation costs. In addition, environmental impacts of irrigation are not always linked with the amount of water used;

b) Increasing block tariffs involves varying the water price when water use for a set time period exceeds a set volume. The amount of the first block is considered as the basic amount of water needed to support a farm. Farmers pay a low rate for the first block but a higher price for subsequent ones. In a similar fashion to volumetric scheme, environmental consequences stemming from irrigation practices are not directly accounted for;

c) Per acre fees: pricing based on area is widespread around the world and, is still the most common pricing method in many developing countries. Basically, farmer's payment refers to the extension of irrigated area regardless of the actual demand of water. In some advanced regions, per area fees are differentiated taking into account the average irrigation requirement of each crop. Per area method can be easily implemented and is relatively less costly than direct methods. With reference to likely shortcoming, criticism rises to the fact that farmers do not have any economic incentive to adopt water-saving technologies;

d) Input pricing: this type of pricing scheme falls into indirect methods, given that payment for irrigation is based on other related inputs, such as seeds, plants, mulching materials, etc. Essentially, it is applied an extra charge to those inputs instead to pay directly for water. To some extent, this scheme is coherent with the polluter pays principle;

e) Output pricing: inversely to input methods, with this scheme payment is due to on the bases of economic value of irrigated production. Similarly to the value added tax, output scheme can be defined as percentage of market value of irrigated crops;

f) Quota: actually, this scheme is not purely considered as pricing method. In fact, with the quota scheme instead to vary price (scheme and/or charge), water allotment is progressively reduced. This method is recognized being more equitable and, in many developing countries is largely applied. Quota can be defined annually, per crop and, sometime under drought condition, on the bases of priority schedules. Inaccurate tariffs setting may lead to economic inefficiency, mostly if water charge results lower than the average marginal productivity.

\section{Materials}

\subsection{Area Description}

The case study relates to a flat area served by irrigation infrastructures, managed by the local irrigation district called 'Consorzio per la Bonifica della Capitanata' (CBC) and located in the south of Italy. The area covers 442 000 ha as a whole, but irrigation infrastructure covers only 135000 ha. The infrastructure consists of a network of underground pipelines through which high-pressure water is conveyed to the farm plots. Therefore, the water supply is available on demand.

Water is stored in a complex system of dams, small rivers and artificial lakes, and annual availability depends strictly upon weather conditions, being an area characterised by a Mediterranean climate with cold wet winters and hot dry summers. Essentially, rainfall varies from 400 to $700 \mathrm{~mm} / \mathrm{year}$, but there are also recurrent periods of 
drought. The annual water stock amounts to 150 million $\mathrm{m}^{3}$, and it is devoted to urban, industrial and agricultural uses. In the case of water shortage urban use is given priority. The irrigation board delivers annually about 106 million $\mathrm{m}^{3}$ to irrigation purposes, but water restrictions are also common depending on rainfall patterns.

As a whole, agriculture is the main water user in the area, accounting for $80 \%$ of renewable resources, and while irrigated areas cover a smaller share of farmland (24\%), in terms of value added, it shares $70 \%$ of total agricultural economic production. Thus, the agricultural sector accounts for $6.8 \%$ of GDP and around $11.7 \%$ of employment (CCIAA, 2009).

The irrigation network was completed in the 1960s. From then, traditional rain fed agriculture based on pastures and winter cereals, has been converting to more intensive agriculture (fresh cut vegetables, processed tomatoes, orchard fruits, olive groves, vineyards), which in turn has also been stimulating the withdrawal of groundwater sources. Indeed private wells have been largely drilled without strict control from the public authority. There is no official data on the actual groundwater extractions, and the share of water use from private wells annually varies according to $\mathrm{CBC}$ availability. Normally it is estimated at $45 \%$, but raises dramatically during exceptionally long drought periods to up to $100 \%$ (D'Arcangelo, Nardella, \& Rodio, 2005).

Water resources from $\mathrm{CBC}$ are allocated through a system of water rights, while groundwater is managed by farmers as a private asset. Although the $\mathrm{CBC}$ is a private consortium of landowners, it is empowered by the public authority (the Apulia Region) to manage the conveyed water from the reservoirs. Landowners have received water use rights by a system coupled with their own land, for an overall amount of water rights which is proportional to the land served by the infrastructure. The use rights are strictly linked with the land and water markets are not allowed. With regard to groundwater, farmers could drill private wells and set all of the necessary equipment for pumping, storage, and delivering water to the crop fields. Lastly, reform to control the excessive exploitation of this resource was introduced in 2008 through the Regional Law No 9 on May 2008 (PUGLIA, L.R.n.9/2008) which introduced the banning of new authorizations and the control by temporal licences for existing wells.

The CBC currently applies a volumetric pricing method, based on an increasing tiered rate system. The revenue collected by the $\mathrm{CBC}$ is currently covering the financial costs only, while resources and environmental costs are still not included. In the case of groundwater, farmers face only the private cost of water extraction.

According to the WFD requirements, the regional environmental agency started in 2008 a monitoring action aimed at defining the status of all water bodies in the region. The actions collected data depicting a critical status of quality worsening, mostly due to the salinization process caused by groundwater overexploitation that has induced the infiltration of sea water. In addition, pollutants such as nitrates, pesticides and organic carbon have been recognized amongst the most important environmental concerns about water quality status (PTA, 2009).

\subsection{Specification of Alternative Water Pricing for the Area Study}

Alternative pricing methods are implemented as follows:

a) P0. Baseline: Water pricing currently consists of a fixed annual fee per hectare (around $15 \mathrm{EUR} / \mathrm{ha}$ ), and an increasing block system of tiered tariffs, therefore farmers pay accordingly to their actual consumption. A tariff of $0.09 € / \mathrm{m}^{3}$ for consumption up to $2050 \mathrm{~m}^{3} / \mathrm{ha}$, and $0.18 € / \mathrm{m}^{3}$ for additional 950 $\mathrm{m}^{3} / \mathrm{ha}$ are applied. Finally, volumes exceeding $3000 \mathrm{~m}^{3} / \mathrm{ha}$ are charged at $0.24 € / \mathrm{m}^{3}$. In the case of groundwater, as abovementioned, farmers carry only the private cost estimated at $0.09 € / \mathrm{m}^{3}$ (Noviello \& Nardella, 2005; Giannoccaro, Prosperi, Valente, \& Zanni, 2009); meanwhile, no resource and environmental costs are due;

b) P1. Full volumetric (Full Vol.): It is assumed that the current three-tiered rate system to CBC water is maintained. In addition, it is hypothesized as the introduction of a simply volumetric method for groundwater, reflecting the resource cost. In absence of any other estimate, a tariff of $0.03 € / \mathrm{m}^{3}$ is assumed. Therefore, farmers will pay the current private cost of $0.09 € / \mathrm{m}^{3}$ plus the new volumetric charge of $0.03 € / \mathrm{m}^{3}$;

c) P2. Input: The introduction of an indirect method in which the water charge is calculated on the input required by irrigated crops is assumed (e.g. plants or seeds, consumable irrigation equipments, ferti-irrigation materials). To reflect an indirect environmental tax on irrigation practices, farmers pay a sort of price surcharge on these inputs, regardless of the actual water consumption (from CBC and groundwater source). The surcharge is different for each crop, and set up on a basis of average crop water consumption;

d) P3. Output: The water consumption is charged proportionally to the gross return from irrigated crops, 
regardless of the water source. The charge rate applied to each crop is calculated as a ratio between the current value of its specific water consumption, and the corresponding gross return (vines $3 \%$, horticultural crops $2.4-2.8 \%$, olive orchards $1.9 \%$ );

e) P4. Area: A per-area pricing is assumed referring to the area suitable for the irrigation practice, regardless of water sources. A per-area hectare charge is set equivalent to the average $\mathrm{CBC}$ cost per hectare of irrigated area $(82 € /$ ha);

f) P5. Quota: A constant water tariff $\left(0.09 € / \mathrm{m}^{3}\right)$ is applied, but subject to a rigid constraint on water availability for each farm. This method is popular among some farmers, as they claim that water prices should remain low and constant, regardless of water availability. Although it is not resulting from a real water market, they accept the concept that the availability may change according to the rainfall regime.

In addition, these water methods are analyzed under different water saving scenarios A, B, C, involving 10, 20 and $30 \%$ of water savings respectively. Tariffs are progressively increased according to pricing methods in order to get the established target of water saving. In the case of the quota scheme, tariffs are kept constant meanwhile water allotments are progressively reduced until each target scenario is obtained. Thus, moving from one pricing policy to another of them would give the policy maker a range of pricing feasibility that can be compared across the 6 pricing schemes that are used. As a whole, 18 water policy options are taken into account for running DEA analysis.

\subsection{Data Collection}

Data are obtained from Giannoccaro, Prosperi and Zanni (2010) where the effects of the water policy scenarios as mentioned above are performed through a linear programming model at the regional level, in which farmers are expected to maximize their profits. In other words, under all irrigation policy hypothesis farmers will pursue the optimal economic allocation of the resource. Therefore, water pricing changes could induce changes in farmers' behaviours towards use of water resource as well as all other farming inputs.

Farms were classified into three main groups according to farm size and cropping patterns (Table 1).

Table 1. Farm typologies in the area

\begin{tabular}{lllll}
\hline & Small & Medium & Large & Total Basin \\
\hline Number of farms & 18,199 & 13,063 & 4,720 & 35,982 \\
Average size (ha) & 2.5 & 10 & 43 & 380,000 \\
Irrigated land (ha) & 1.2 & 2.9 & 11.6 & 80,000 \\
Share on Basin farmland (\%) & 10 & 30 & 60 & 100 \\
Share on Basin irrigated land (\%) & 3 & 47 & 50 & 100 \\
Cropping patterns (within farm) & & & & \\
Durum wheat & $40 \%$ & $68 \%$ & $75 \%$ & \\
Orchards & $50 \%$ & $20 \%$ & $9 \%$ & \\
Vegetables & $3 \%$ & $7 \%$ & $7 \%$ & \\
Others & $7 \%$ & $5 \%$ & $9 \%$ & \\
\hline
\end{tabular}

Source: Adapted from ISTAT (2000).

The resource constraint for water is specified in order to align with the water delivery schedule from the CBC (monthly), which delivers some 106 million $\mathrm{m}^{3}$ between April and November. In the case of the non-CBC water source, there are constraints with regard to delivery, and availability is estimated at 89 million $\mathrm{m}^{3}$ at the most.

The regional model is performed under short period assumptions with farm size and water rights being set as constant. As a consequence, the decision variables of the model are basically referred to the optimal cropping mix, which determines the utilization of production inputs (land, labour and capital) including water and chemicals, as well as economic outputs measured in terms of value added.

From the optimal solution of each water policy option, the variables of input, output and externalities are obtained. Detail of variables units are hold in Table 2. 
Conventional inputs are land, labour, capital and water. The latter variable accounts for both surface water delivered by the CBC, and groundwater withdrawals. Value added refers to the difference between gross output (i.e. economic value of productions at the market prices) and intermediate consumptions (i.e. goods and services) used. Intermediate costs refer to seeds, fertilizers, pesticides, energy, and other services used in the farming processes. Finally, CAP regime and its relative financial supports are not included in the value added. Thus, it is a measure of the contribution of the agriculture (irrigated and rain fed as a whole) to the economic wealth.

Table 2. Inputs, output and externalities

\begin{tabular}{|c|c|c|c|c|c|c|c|}
\hline & \multicolumn{5}{|c|}{ Conventional Resources } & \multicolumn{2}{|c|}{ Environmental Externalities } \\
\hline & Input & & & & Desirable Output & Undesirable out & uts \\
\hline & Land & Labour & Capital & Water & Value added & Pesticides Risk & $\begin{array}{l}\text { Nitrogen } \\
\text { Surplus }\end{array}$ \\
\hline Units & $10^{3}$ hectares & $10^{3}$ hours & $10^{6} \mathrm{EUR}$ & $10^{6} \mathrm{~m}^{3}$ & $10^{6} \mathrm{EUR}$ & $10^{3} \mathrm{Kg}$ & $10^{6} \mathrm{t}$ \\
\hline
\end{tabular}

Source: own elaboration

Pesticide risk $p_{j c}$ for crop $c$ is modelled as follow:

$$
p_{j c}=\sum_{t} a_{j t} 1000000 / D L 50_{t}
$$

Where $a_{j t}$ amount of active matter $t$ by unit of pesticide $j$; DL $50_{\mathrm{t}}$ is the lethal dose 50 of the active matter $t$ usually reported on commercial product. The indicator represents the weight (in kilograms) of the population of rats, $50 \%$ of which would be potentially killed by $1 \mathrm{Kg} / \mathrm{L}$ of the pesticide. In this context it represents a proxy of the environmental hazard (for chief details see OECD, 2001, p. 149).

Nitrate surplus is the physical difference between nitrogen inputs and outputs from an agricultural system, per hectare of agricultural land (see OECD, 2001, p. 20).

Data on pesticides risk and nitrate surplus are from Giannoccaro et al. (2009). Values are calculated for each crop (per hectare of farmland) on the basis of technical and agronomic farming practices normally adopted by farmers in the area.

All the above variables are referred to the agricultural system as the aggregation of overall farms. The pay-off matrix obtained through the simulation process is reported in the appendix.

\section{Methodology}

Two main techniques are suitable for the analysis of the efficiency: the stochastic frontier analysis (SFA) and the data envelopment analysis (DEA). The typical statistical approach to evaluate the efficiency is characterised as a central-tendency approach, which evaluates producers relative to an average producer. To do that, in SFA the shape of function is prior defined. In contrast, DEA is an extreme-point method and compares each producer with only the 'best' producers ${ }^{1}$. This methodology is useful whenever there is no information about the relative importance among outputs or inputs, as it does not require assumptions a priori (Callens \& Tyteca, 1999). Additionally, DEA deals with variables regardless of their unit measure, provided that these units are the same for every entity (Coelli, Prasada Rao, \& Batteste, 1997). In this regard, we adopted the DEA since our research encompasses ecological aspects therefore, the unnecessary assignment of weights for environmental resources and impacts, allows us to proceed with a more objective analysis.

The first non-parametric analysis to compare multiple desirable and undesirable outputs is reported in Färe, Grosskopf, Lovell and Pasurka (1989). However, the general emphasis on the environmental issue has occurred later (Tyteca 1996, presents an exhaustive literature review), where externalities have usually been treated as 'undesirable outputs' of the production process (e.g., Fernandez-Cornejo 1994; Tyteca, 1996; Piot-Lepetit, Vermersch, \& Weaver, 1997). Another possibility is to envision the undesirable outputs as inputs (see Seiford and Zhu (2002) for either approach). As in De Koeijer, Wossink, Struik and Renkema (2002) here environmental effects are modelled as conventional inputs.

In the present research, the DEA method is adopted with the aim of measuring the eco-efficiency of different irrigation pricing policies, as first applied by Korhonen and Luptacik (2004). Korhonen and Luptacik (2004) measured the eco-efficiency of 24 power plants in Europe in two steps. Essentially, conventional efficiency and 
the so-called environmental efficiency are estimated separately, then, by combining both efficiencies, the eco-efficiency score is obtained.

As mentioned in the introduction, eco-efficiency here is defined as the ratio between economic value added and environmental pressures. Indeed, this paper focuses on a broader measure of productivity (i.e. economic value added), which is achieved by using all the resources (capital, labour, land and water) available. At the same time, externalities (i.e. nitrate surplus and pesticides risk) are also taken into account ${ }^{2}$. The final result consists of an efficiency score that takes into account all resources used, as well as the externalities released to the environment. By construction, this score of eco-efficiency is upper bounded to one, the score that represents best performance. Moreover, the lower the score computed the lower eco-efficiency. Scores computed measures eco-efficiency in a Farrell-Debreu sense (Farrell, 1957), as they are assessing equiproportional or radial reductions of environmental pressures necessary to attain eco-efficiency.

Let us consider the $n$ water pricing policies and the effects simulated, namely the amount of $m$ inputs and $k$ outputs estimated through the mathematical programming model. In particular, for $m=1,2, \ldots i$, the subscript for production inputs is assigned (here land, labour, capital and water), while for $m=i+1, i+2, \ldots p$, the externalities are specified (here nitrate surplus and pesticide risk indicators are seen as inputs); at the same time, for $k=1,2, . ., r$, the subscript for conventional outputs is identified (here value added).

Firstly, the relative economic efficiency is performed by the Input-Oriented CRS model which assumes constant returns of scale ${ }^{3}$. In this step the efficiency of the policy ' $O^{\prime}\left(h_{0}\right)$ is calculated through a linear programming model whose optimal solution provides the (positive) weights to be applied to outputs $\left(\mu_{r}\right)$ and inputs $\left(v_{i}\right)$, in order to find a ratio of output on inputs that ranges from 0 to 1 :

$$
\begin{aligned}
& \operatorname{Max} \mathrm{h}_{0}=\left(\Sigma_{r=1}^{k} \mu_{r} \mathrm{y}_{r} 0\right) /\left(\Sigma_{i=1}^{m} v_{i} \mathrm{x}_{i 0}\right) \\
& \text { s.t. } \\
& \left(\Sigma_{r=1}^{k} \mu_{r} \mathrm{y}_{r j}\right) /\left(\Sigma_{i=1}^{m} v_{j} \mathrm{x}_{i j}\right)<=1, \mathrm{j}=1,2, \ldots, \mathrm{n} \\
& \mu_{r}, v_{j}=>\varepsilon, \mathrm{r}=1,2, \ldots, \mathrm{k} ; \mathrm{i}=1,2, \ldots, \mathrm{m} \\
& \varepsilon>0 \text { (Non-Archimedean) }
\end{aligned}
$$

Scores of radial efficiency, which in turn represents the proportional potential reduction of all conventional inputs (land, labour, capital and water) while value added are held constant, have been estimated by solving expression (2) for each water policy.

Secondly, the measurement of the environmental efficiency $\left(g_{0}\right)$, through the calculation of the weights to be applied to the desirable outputs $\left(\mu_{r}\right)$ and the undesirable outputs $\left(\mu_{s}\right)$ is run according to the follow equation:

$$
\begin{aligned}
& \operatorname{Max} \mathrm{g}_{0}=\left(\Sigma_{r=1}^{k} \mu_{r} \mathrm{y}_{r 0}\right) /\left(\Sigma_{s=m+1}^{p} \mu_{\mathrm{s}} \mathrm{y}_{s}\right) \\
& \text { s.t. } \\
& \left.\quad \Sigma_{r=1}^{k} \mu_{r} \mathrm{y}_{r j}\right) /\left(\Sigma_{s=m+1}^{p} \mu_{s} \mathrm{y}_{s j}\right)<=1, \mathrm{j}=1,2, \ldots, \mathrm{n} \\
& \mu_{r}=>\varepsilon, \mathrm{r}=1,2, \ldots, \mathrm{p} \\
& \varepsilon>0 \text { (Non-Archimedean) }
\end{aligned}
$$

Specific environmental efficiency scores by policies have been calculated according to the expression (3).

At this point, it is possible to combine the results of both models as the output variables for the new DEA model (with the inputs equal to 1), in order to find an indicator for eco-efficiency.

The input-oriented version of this model estimates eco-efficiency by reducing both inputs and undesirable outputs while keeping desirable outputs constant. The eco-efficiency score thus indicates the extent to which both inputs and undesirable outputs can be reduced simultaneously.

\section{Results and Discussion}

This section reports and discusses firstly economic and environmental efficiency separately then the eco-efficiency analysis is shown. Table 3 shows the results of the DEA analysis. 
Table 3. Efficiency scores for several policy options

\begin{tabular}{lll}
\hline Policy options & $\begin{array}{l}\text { Economic } \\
\text { efficiency }\end{array}$ & $\begin{array}{l}\text { Environmental } \\
\text { efficiency }\end{array}$ \\
\hline A_P0.Baseline & 0.95658 & 0.95729 \\
A_P1.Full_Vol. & 0.95658 & 0.95729 \\
A_P2.Input & 0.97913 & 0.95701 \\
A_P3.Output & 0.98335 & 1.00000 \\
A_P4.Area & 1.00000 & 1.00000 \\
A_P5.Quota & 0.96723 & 0.96360 \\
\hline B_P0.Baseline & 0.93426 & 0.89527 \\
B_P1. Full_Vol. & 0.93466 & 0.89438 \\
B_P2.Input & 0.96018 & 0.88980 \\
B_P3.Output & 0.95065 & 0.88523 \\
B_P4.Area & 1.00000 & 0.92847 \\
B_P5.Quota & 0.88918 & 0.85174 \\
\hline C_P0.Baseline & 0.94600 & 0.86403 \\
C_P1. Full_Vol. & 0.95582 & 0.87217 \\
C_P2.Input & 0.98499 & 0.81452 \\
C_P3.Output & 0.90537 & 0.75500 \\
C_P4.Area & 0.94834 & 0.79116 \\
C_P5.Quota & 0.87474 & 0.77874 \\
\hline
\end{tabular}

Source: Own elaboration.

\subsection{Economic Efficiency}

On the basis of economic efficiency scores (first column in Table 3), only two options out of the 18 simulated reach rate 1 , being the best efficiency score. They correspond to water pricing based on per area, at the water saving scenarios A and B. The lowest score is reached by the quota pricing for a $30 \%$ water saving (scenario C) with a value of 0.87474 . The average efficiency of the sample is 0.95150 while median is 0.95620 , and generally slight differences are found with the standard deviation being 0.035 . According to these results it is not proven that the implementation of volumetric pricing will necessarily lead to a higher economic efficiency in comparison to other methods.

These outcomes show, in the first place, that water policy options taken into account here are rather efficient. These findings imply that there exists little difference in terms of technical efficiency among the different water pricing options. Thus, water policy reforms in the study area could scarcely increase efficiency of irrigated agricultural and, therefore of the agricultural system as a whole.

Nevertheless, some consideration should be discussed. Firstly, it should be noticed that while only 8 out of 18 options have a score lower than the mean or median, all of these fall into $\mathrm{B}$ and $\mathrm{C}$ water charge scenarios. Likewise, the per-area scheme which is the best option under A and B saving scenarios turns to an inefficient score in the case of scenario C. Indeed, it loses almost $6 \%$ of efficiency. B and C scenarios respectively consider a water reduction at basin level of 20 and $30 \%$ with respect to the current use, therefore powering water saving via pricing charges, does not seem lead to an improved (economic) efficiency of the agricultural sector. Secondly, current systems of water charge (Baseline) reach efficiency levels always under the mean. Regardless of the water saving scenario, the increasing block system currently implemented in the area is not efficient enough.

\subsection{Environmental Efficiency}

Environmental efficiency provides an indication of how the externalities can be reduced in the production process of agricultural systems, while continuing to produce the same value added. 
The average efficiency of the sample (Table 3, column at right) is 0.89198 with the median at 0.89209 . Generally, major differences are found when comparing this ranking with the one obtained by accounting only for economic aspects. In fact, the standard deviation is 0.074 and 9 out of 18 water options reach scores lower than the mean or median. Finally, only 2 out of 18 options are the most efficient, Area-based and Output-based methods. Both methods reach the highest level under water charge scenario A.

On the other hand, the worst efficiency level is shown in the case of the Output-based pricing alternative in the water saving scenario C, where almost $25 \%$ of inefficiency with respect to the most efficient alternative is found. Quota methods are always inefficient, regardless of the water saving scenario. The input pricing method reaches a lower efficiency due to an excess of environmental externalities.

Taking into account the most efficient options, it should be noticed that all water pricing policies take place in the water saving scenario A. At the same time, water saving scenarios B and C hold the worst options.

As in the case of economic efficiency, findings here suggest that an increase in water pricing charges does not result in an environmental efficiency improvement. In this regard, changes in the environmental impacts as well as value added for the Baseline pricing method are reported in Figure 1, where the 'status-quo' indicates the current level for the three variables, and the levels A, B, and C, report the change in these variables according to the water saving scenarios. As figure shows, the externalities (i.e. Nitrate surpluses and Pesticides risk) show a smaller decrease with respect to the value added along the water saving scenarios. As a consequence, if the enforcement of tariffs is applied value added goes down more than nitrate and pesticides indicators.

The fact that the overall-use of other non-water inputs decreases together with water use is found in most studies (Gómez-Limón, Riesgo \& Arriaza, 2004; Manos et al., 2006; Bartolini, Bazzani, Gallerani, Raggi, \& Viaggi, 2007; Speelman et al., 2009). Nevertheless, our approach allows for assessing the most efficient water pricing that ensures reducing these externalities as little as possible meanwhile the value added is held constant.

Overall, findings point out that a pricing system based on per area and output will lead to the highest efficiency although this is not valid under any water pricing charge. At the same time, this implies that the current pricing method (Baseline) is not the most environmentally efficient.

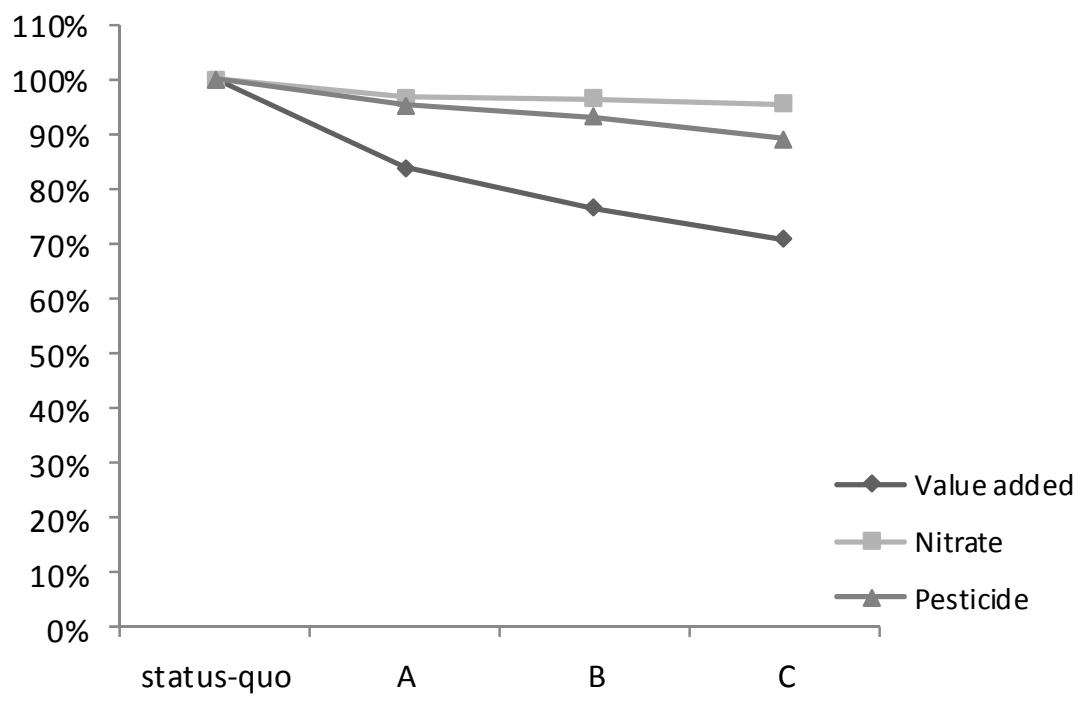

Figure 1. Change in value added, Nitrate and Pesticides indicatorsaccording to water saving scenarios for the Baseline pricing scheme

\subsection{Eco-Efficiency}

We turn now to the analysis of both economic and environmental efficiency simultaneously (i.e. second step of modified DEA technique). The eco-efficiency scores of different water pricing policies are presented in Table 4 . 
Table 4. Computed score of eco-efficiency

\begin{tabular}{llllll}
\hline A_P0.Baseline & 0.95729 & B_P0.Baseline & 0.93426 & C_P0.Baseline & 0.94600 \\
\hline A_P1. Full_Vol. & 0.95729 & B_P1. Full_Vol. & 0.93466 & C_P1. Full_Vol. & 0.95582 \\
A_P2.Input & 0.97913 & B_P2.Input & 0.96018 & C_P2.Input & 0.98499 \\
A_P3.Output & 1.00000 & B_P3.Output & 0.95065 & C_P3.Output & 0.90537 \\
A_P4.Area & 1.00000 & B_P4.Area & 1.00000 & C_P4.Area & 0.94834 \\
A_P5.Quota & 0.96723 & B_P5.Quota & 0.88918 & C_P5.Quota & 0.87474 \\
\hline
\end{tabular}

Source: own elaboration.

From the findings in Table 4, only three options out of the 18 simulated reach the highest eco-efficiency levels. They are the options A_P4.Area, B_P4.Area and A_P3.Output. It should be stressed that two out of three best options are pricing schemes based on per area, and two out of the three best options fall into the saving scenario $\mathrm{A}$; the water saving scenario $\mathrm{C}$ does not account for any option. Again, the lowest score is reached by the quota method in the case of the water saving scenario $\mathrm{C}$, with a value of 0.87474 . The average eco-efficiency of the sample is 0.94924 while median is 0.95065 , and generally slight differences are found with the standard deviation being 0.036 . Finally, 7 out of 18 options have a score lower than the mean or menidan and, all of these, fall into $\mathrm{B}$ and $\mathrm{C}$ water saving scenarios.

According to the results of this analysis, it is not proven that the implementation of the volumetric pricing will necessarily lead to a higher eco-efficiency in comparison to other methods. The main result of this research is that the area-based pricing method is the most eco-efficient. At the same time, the output method where the water payment is linked with the economic return of irrigated crops emerges as an interesting alternative. Finally, as expected from the literature the quota scheme is always the least efficient.

Basically, while the results point out the relatively small magnitude of gains in eco-efficiency derived from the water policy reforms, major concerns arise from the charge levels, at which pricing policies are set. Indeed, both economic and environmental efficiency do not show any efficiency improvement if the water tariffs are enforced regardless of the pricing schemes implemented. This aspect is again found for the eco-efficiency indicators which combine the two previous indicators. If the charge is increased, only per area pricing shows an efficient performance, although extreme enforcement which takes place under the scenario $\mathrm{C}$ produces the same efficiency loss.

In regard to pricing schemes currently adopted within the irrigation basin (Baseline), findings here show that the present situation is not the most efficient, although magnitude of improvement in eco-efficiency by introducing a new pricing scheme (i.e. per area charge) is at least less than $5 \%$. However, it is worth mentioning that the eco-efficiency score here refers to the overall agricultural sector thus smaller variation in the eco-efficiency score can results in larger reduction of inputs and environmental impacts, meanwhile the value added is kept constant.

In addition, taking into account the fact that volumetric schemes might imply an inherent additional cost and, since indirect methods, namely per area schemes are claimed to be easily implemented (Tsur \& Dinar, 1997), they might be preferable, without significant losses in terms of efficiency.

In order to determine whether the final eco-efficiency score is mainly linked with the economic or environmental aspects, the Spearman's rank correlation coefficient $(R)$ is computed, which is useful to determine the measure of association between ranks obtained by two different approaches (Gibbons, 1971). Spearman $R$ values of 1, 0 and -1 , represent perfect association, no association and perfect disagreement respectively between the approaches. The result of non parametric test is 0.91 between the economic efficiency and eco-efficiency scores, meanwhile environmental efficiency and eco-efficiency reports a value of 0.61 . This means that the radial eco-efficiency of water policies is highly correlated with the economic efficiency. On the other hand, it has been confirmed that environmental impacts are not always related to the water use, and water pricing, even more water pricing enforcement may not be suitable to increase the environmental efficiency. Thus, under the research circumstances, the agricultural performance in the area may be slightly driven by a water pricing reform. Other policy instruments such as incentives, tradable permits, tax, standard emission or compliance like in the case of CAP should receive more attention.

Finally, the comparison of the set options shows that their effect is not straightforward assuming a static 
framework for decision-making, which also justifies further research in this direction. This can also be caused by several issues related to the case study, such as climate condition that makes the elasticity of water substitution among other production inputs very low, reducing the room for farm adaptation.

\section{Concluding Remarks}

The reform of water pricing methods is one of the most re-called requirements for the enhancement of the efficiency of using water and of its quality status. In order to change the pricing schemes as well as the charges, policy makers require a clear overview of the different outcomes deriving from alternative water management policies, and tools aimed at decision support are needed in order to select the most suitable option.

In the present paper the relative economic and environmental efficiency of an agricultural system subject to alternative water pricing policies has been estimated using a methodology based on DEA. Water pricing policy has been evaluated taking into account economic and environmental goals in order to enhance the optimal pricing scheme as well as charging water sources considering the main agricultural system needs, in accordance with the ecological and economic principles of the WFD.

DEA evaluation overcomes the usual trade-off or compromise amongst the conflicting objectives as economic and environmental issues, taking into account the eco-efficiency as criteria for the options ranking.

The results obtained for the case study suggest that the potential gains of economic efficiency among the different water pricing options are relatively small. However, higher environmental efficiency gains could be achieved from water pricing scheme reforms. Despite the fact that the implementation of the volumetric pricing was expected to lead to a higher eco-efficiency, the area-based pricing method has proven to be the most eco-efficient in this case study. The output method also emerges as an interesting alternative. The enforcement of water saving via pricing charges does not imply a higher efficiency, mainly in the case of environmental efficiency.

For current pricing systems, if the 'full cost recovery' principle prescribed in the WFD is applied via a rise in price, the result will be a decrease in eco-efficiency. This aspect is crucial in the Capitanata area as well as in other Mediterranean regions where water for irrigation accounts for $70-80 \%$ of total water consumption.

\section{Acknowledgements}

This research was conducted in the context of the Italian Ministry of University and Research-PRIN 2008, DM n. 1407 del 4 dicembre 2008, prot. 200838S29Y_005, 'Economic analysis of the water management and of the opportunity cost, in areas of scarce water availability'. The work of Francisco Alcón was financed by the Spanish Ministry of Education and Science and the ERDF through the GEAMED project (AGL2010-22221-C02-01). The work of Dr. Julia Martin-Ortega was financed by the Scottish Government Rural Affairs and the Environment Portfolio Strategic Research Programme 2011-2016, Theme 2, WP2.3. 'Effectiveness of measures to manage water quality'. Finally, authors are grateful for comments recieved from editor and anonymous referees, which allowed improving the first version of paper.

\section{References}

Bartolini, F., Bazzani, G. M., Gallerani, V., Raggi, M., \& Viaggi, D. (2007). The impact of water and agriculture policy scenarios on irrigated farming systems in Italy: an analysis based on farm level multi-attribute linear programming models. Agricultural Systems, 93, 90-114. http://dx.doi.org/10.1016/j.agsy.2006.04.006

Bazzani, G. M., Di Pasquale, S., Gallerani, V., \& Viaggi, D. (2004). Irrigated agriculture in Italy and water regulation under the European Union Water Framework Directive. Water Resources Research, 40(7), W07S04. http://dx.doi.org/10.1029/2003WR002201

Bono, F., \& Matranga, D. (2005). Measures of efficiency in the environmental context. In S.I.S. 2005 - Statistica e Ambiente. Messina, Italy 21-23 September 2005.

Burt, C. M. (2007). Volumetric irrigation water pricing considerations. Irrigation Drainage System, 21, 133-144. http://dx.doi.org/10.1007/s10795-007-9025-3

Callens, I., \& Tyteca, D. (1999). Towards indicators of sustainable development for firms: a productive efficiency perspective. Ecological Economics, 28(1), 41-53. http://dx.doi.org/10.1016/S0921-8009(98)00035-4

CCIAA (Camera di Commercio Industria Artigianato Agricoltura). (2009). Rapporto economico 2007-2008. Foggia, Italy: Osservatorio Economico Provinciale.

Charnes, A., Cooper, W., \& Rhodes, E. (1978). Measuring the efficiency of decision-making units. European Journal of Operational Research, 2, 429-444. http://dx.doi.org/10.1016/0377-2217(79)90229-7 
Coelli, T., Prasada Rao, D. S., \& Batteste, G. E. (1997). An introduction to efficiency and productivity analysis. Boston: Kluwer Academic Publishers.

Cooper, W. W., Seiford, M. L., \& Tone, K. (2000). Data Envelopment Analysis. Boston/Dordrecht/London: Kluwer Academic Publishers.

D'Arcangelo, G., Nardella, L., \& Rodio, M.E. (2005). Analysis of water requirement and consumptions in a public district of recent irrigation: The case of sub districts 5b, 12 and 13. Bonifica, 4, 34-42.

De Koeijer, T. J., Wossink, G. A. A., Struik, P. C., \& Renkema, J. A. (2002). Measuring agricultural sustainability in terms of efficiency: the case of Dutch sugar beet growers. Journal of Environmental Management, 66, 9-17. http://dx.doi.org/10.1006/jema.2002.0578

Dinar, A., \& Subramanian, A. (1997). Water pricing experience, World Bank Technical Paper 386. Washington, DC: World Bank.

Dono, G., Giraldo, L., \& Severini, S. (2010). Pricing of irrigation water under alternative charging methods: Possible shortcoming of a volumetric approach. Agricultural Water Management, 97, 1795-1805. http://dx.doi.org/10.1016/j.agwat.2010.06.013

Dworak, T., Berglund, M., Laaser, C., Strosser, P., Roussard, J., Grandmougin, B., ... Montesinos, P. (2007). EU Water Saving Potential, Report prepared for the EU Commission, Brussels. ENV.D.2/ETU/2007/0001r. Berlin, Germany.

Easter, K. W., \& Liu, Y. (2005). Cost recovery and water pricing for irrigation and drainage projects. Agriculture and Rural Development, Discussion Paper No 20. Washington, DC: World Bank.

Färe, R., Grosskopf, S., Lovell, C. A. K., \& Pasurka, C. (1989). Multilateral productivity comparisons when some outputs are undesirable: a nonparametric approach. Review of Economics and Statistics, 71, 90-98.

Farrell, M. J. (1957). The measurement of productive efficiency. Journal of the Royal Statistical Society, Series A, General, 120, 253-281. http://dx.doi.org/10.2307/1928055

Fernandez-Cornejo, J. (1994). Nonradial technical efficiency and chemical input use in agriculture. Agricultural and Resource Economics Review, 22, 11-21.

Giannoccaro, G., Prosperi, M., \& Zanni, G. (2010). Assessing the impact of alternative water pricing schemes on income distribution. Journal of Agriculural Economics, 61(3), 527-544. http://dx.doi.org/10.1111/j.1477-9552.2010.00252.x

Giannoccaro, G., Prosperi, M., Valente, N., \& Zanni, G. (2009). Valutazione degli impatti della politica di tariffazione delle acque irrigue sull'agricoltura della Capitanata (Puglia). In V. Gallerani, G. La Via \& G. Zanni (Eds.), Acqua e Agricoltura in Italia. Valutazioni di scenari e strumenti di supporto alle decisioni (pp. 121-149). Milan, Italy: Franco Angeli.

Gibbons, J. D. (1971). Nonparametric Statistical Inference. New York: McGraw-Hill.

Gómez-Limón, J. A., Riesgo, L., \& Arriaza, M. (2004). Multi-Criteria analysis of input use in agriculture. Journal of Agricultural Economics, 55, 541-564. http://dx.doi.org/10.1111/j.1477-9552.2004.tb00114.x

Gómez-Limón, J. A., \& Sanchez-Fernandez, G. (2010). Empirical evaluation of agricultural sustainability using $\begin{array}{llll}\text { composite indicators. } & \text { Ecological }\end{array}$ http://dx.doi.org/10.1016/j.ecolecon.2009.11.027

ISTAT (Istituto Nazionale di Statistica). (2001). $5^{\text {th }}$ Censimento nazionale dell'agricoltura. Rome, ISTAT.

Johansson, R. C., Tsur, Y., Roe, T. L., Doukkali, R., \& Dinar, A. (2002). Pricing irrigation water: a review of theory and practice. Water Policy, 4(2), 173-199. http://dx.doi.org/10.1016/S1366-7017(02)00026-0

Korhonen, P. J., \& Luptacik, M. (2004). Eco-efficiency analysis of power plants: An extension of data envelopment analysis. European Journal of Operational Research, 154, 437-446. http://dx.doi.org/10.1016/S0377-2217(03)00180-2

Kuosmanen, T., \& Kortelainen, M. (2005). Measuring eco-efficiency of production with Data Envelopment Analysis. Journal of Industrial Ecology, 9, 59-72. http://dx.doi.org/10.1162/108819805775247846

Malano, H. M., \& Burton, M. (2001). Guidelines for benchmarking performance in the irrigation and drainage sector. International Program for Technology Research in Irrigation and Drainage. Secretariat - Technology \& Engineering. Rome: FAO. 
Manos, B., Bournaris, T., Kamruzzaman, M., Begum, M., Anjuman, A., \& Papathanasiou, J. (2006). Regional Impact of irrigation water pricing in Greece under alternative scenarios of European Policy: a multicriteria analysis. Regional Studies, 40(9), 1055-1068. http://dx.doi.org/10.1080/00343400600928335

Martin-Ortega, J., (2012). Economic prescriptions and policy applications in the implementation of the European Water Framework Directive. Environmental Science and Policy, 24, 83-91. http://dx.doi.org/10.1016/j.envsci.2012.06.002

Martínez, Y., \& Albiac, J. (2004). Agricultural pollution control under Spanish and European environmental policies. Water Resources Research, 40, W10501. http://dx.doi.org/10.1029/2004WR003102

Messner, F. (2006). Applying participatory multicriteria methods to river basin management: improving the implementation of the Water Framework Directive. Environment and Planning C: Government and Policy, 24(2), 159-167. http://dx.doi.org/10.1068/c2402ed

Musolino G., \& Rindone C. (2009). An integrated LUTI and DEA procedure for strategic urban transport planning. Proceedings of the European Transport Conference, Association of European Transport. Noordwijkerhout (NLD), 5-7 October 2009.

Molle, F., Venot, J. P., \& Hassan, Y. (2008). Irrigation in the Jordan Valley: Are water pricing policies overly optimistic? Agricultural Water Management, 95, 427-438. http://dx.doi.org/10.1016/j.agwat.2007.11.005

Molle, F., \& Berkoff, J. (2007). Irrigation water pricing. The gap between theory and practice. Wallingford, UK: IWMI/CABI. http://dx.doi.org/10.1079/9781845932923.0000

Noviello, N., \& Nardella, L. (2005). I costi di produzione negli ordinamenti produttivi della Capitanata: Incidenza dell'acqua e dell'irrigazione. Bonifica, 4, 17-49.

OECD. (2001). Environmental indicators for agriculture. Volume 3 - Methods and Results. Paris: OECD.

Ortega, J. F., de Juan, J. A., \& Tarjuelo, J. M. (2004). Evaluation of the water cost effect on water resource management: application to typical crops in a semiarid region. Agricultural Water Management, 66, 125-144. http://dx.doi.org/10.1016/j.agwat.2003.10.005

O'Shea, L. C. M., \& Wade, A. J. (2009). Controlling nitrate pollution: An integrated approach. Land Use Policy, 26(3), 799-808. http://dx.doi.org/10.1016/j.landusepol.2008.10.017

Picazo-Tadeo, A., Gómez-Limóm, J. A., \& Reig-Martínez, E. (2011). Assessing farming eco-efficiency: A Data Envelopment Analysis approach. Juornal of Environmental Management, 92, 1154-1164. http://dx.doi.org/10.1016/j.jenvman.2010.11.025

Piot-Lepetit, I., Vermersch, D., \& Weaver, R. D. (1997). Agriculture's environmental externalities: DEA

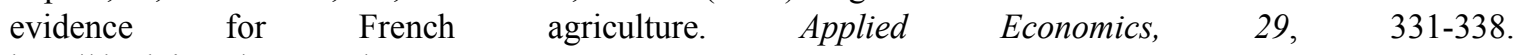
http://dx.doi.org/10.1080/000368497327100

PTA (Piano di Tutela Acque). (2009). Bollettino Ufficiale della Regione Puglia 2009, 130 suppl., 4-8. Italy: Regione Puglia.

Raju, K. S., \& Kumar, D. N. (2006). Ranking irrigation planning Alternatives Using data Envelopment Analysis.Water Resources Management, 20, 553-566. http://dx.doi.org/10.1007/s11269-006-3090-5

Seiford, L. M., \& Zhu, J. (2002). Modeling undesirable factors in efficiency evaluation. European Journal of Operational Research, 142, 16-20. http://dx.doi.org/10.1016/S0377-2217(01)00293-4

Speelman, S., Buysse, J., Farolfi, S., Frija, A., D'Haese, M., \& D’Haese, L. (2009). Estimating the impacts of water pricing on smallholder irrigators in North West Province, South Africa. Agricultural Water Management, 96, 1560-1566. http://dx.doi.org/10.1016/j.agwat.2009.06.014

Tsur, Y., \& Dinar, A. (1995). Efficiency and Equity Considerations in Pricing and Allocating Irrigation Water. Policy Research Paper 1460. Washington, DC: World Bank.

Tsur, Y., \& Dinar, A. (1997). The relative efficiency and implementation costs of alternatives methods for pricing irrigation water. The World Bank Economic Review, 11, 243-262. http://dx.doi.org/10.1093/wber/11.2.243

Tyteca, D. (1996). On the Measurement of the Environmental Performance of Firms- A Literature Review and a Productive Efficiency Perspective. Journal of Environmental Management, 46, 281-308. http://dx.doi.org/10.1006/jema.1996.0022

Viaggi, D., Raggi, M., Bartolini, F., \& Gallerani, V. (2010). Designing contracts for irrigation water under asymmetric information: Are simple pricing mechanisms enough? Agricultural Water Management, 97, 
1326-1332. http://dx.doi.org/10.1016/j.agwat.2010.03.014

Volk, M., Lierscha, S., \& Schmidt, G. (2009). Towards the implementation of the EuropeanWater Framework Directive? Lessons learned from water quality simulations in an agricultural watershed. Land Use Policy, 26, 580-588. http://dx.doi.org/10.1016/j.landusepol.2008.08.005

\section{Notes}

Note 1. For a more in-depth discussion of DEA, the interested reader is referred to Cooper, Seiford, \& Tone (2000) or the seminal work by Charnes, Cooper and Rhodes (1978).

Note 2. Nitrate surplus and pesticide risk were chosen as indicators of the main agriculture pressures on the region according to the assessment carried out by the regional environmental agency (see PTA, 2009). In this regards, environmental variables should be referred to the relevant environmental issues according to each case study.

Note 3. By relying on input oriented efficiency measures the approach takes an input perspective. Farmers maximize profit and respond to water policy changes by changing their cropping mix, which in turn affects the inputs use on farm. In addition, it is assumed that the farming exhibits constant returns to scale (CRS). In fact, under the short period assumptions they are constrained by the technology frontier and their individual constrains (i.e. farm size and water rights), so that the inefficiency scale does not face.

\section{Appendix}

Pay-off matrix

\begin{tabular}{lccccccc}
\hline & Land & Labour & Capital & Water & $\begin{array}{c}\text { Value } \\
\text { added }\end{array}$ & $\begin{array}{c}\text { Pesticides } \\
\text { Risk }\end{array}$ & $\begin{array}{c}\text { Nitrogen } \\
\text { surplus }\end{array}$ \\
\cline { 2 - 8 } & $\begin{array}{c}10^{3} \\
\text { hectares }\end{array}$ & $10^{3}$ hours & $10^{6} \mathrm{EUR}$ & $10^{6} \mathrm{~m}^{3}$ & $10^{6} \mathrm{EUR}$ & $10^{3} \mathrm{Kg}$ & $10^{6} \mathrm{t}$ \\
\hline A_P0.Baseline & 372.698 & 20.757 & 176.148 & 170.414 & 71.402 & 705.016 & 33.624 \\
A-P1. Full_Vol. & 372.698 & 20.757 & 178.156 & 170.408 & 71.402 & 705.016 & 33.624 \\
A_P2.Input & 377.059 & 21.149 & 179.222 & 174.433 & 74.464 & 758.586 & 32.519 \\
A_P3.Output & 378.848 & 21.416 & 180.039 & 172.648 & 75.731 & 784.552 & 31.163 \\
A_P4.Area & 379.525 & 21.852 & 181.568 & 171.276 & 78.580 & 742.750 & 33.088 \\
A_P5.Quota & 372.730 & 20.841 & 175.844 & 173.911 & 72.488 & 711.049 & 33.802 \\
\hline B_P0.Baseline & 373.253 & 20.280 & 172.841 & 151.474 & 65.153 & 687.872 & 33.545 \\
B_P1. Full_Vol. & 373.261 & 20.271 & 175.176 & 151.112 & 65.035 & 687.311 & 33.539 \\
B_P2.Input & 377.747 & 20.671 & 175.828 & 152.667 & 67.545 & 745.416 & 31.669 \\
B_P3.Output & 378.149 & 20.559 & 175.246 & 151.456 & 66.356 & 762.805 & 30.990 \\
B_P4.Area & 378.783 & 21.188 & 177.903 & 152.575 & 70.438 & 725.091 & 31.860 \\
B_P5.Quota & 371.990 & 19.878 & 169.409 & 152.655 & 62.366 & 692.107 & 33.350 \\
\hline C_P0.Baseline & 372.403 & 19.872 & 168.535 & 137.826 & 60.193 & 658.483 & 33.208 \\
C_P1. Full_Vol. & 372.332 & 19.926 & 171.483 & 136.952 & 60.432 & 654.936 & 33.166 \\
C_P2.Input & 377.479 & 20.097 & 171.487 & 132.227 & 60.127 & 718.277 & 30.867 \\
C_P3.Output & 376.850 & 19.494 & 169.023 & 133.793 & 55.922 & 736.342 & 30.806 \\
C_P4.Area & 376.966 & 19.933 & 168.814 & 134.222 & 58.764 & 703.896 & 31.256 \\
C_P5.Quota & 371.382 & 19.272 & 164.871 & 137.479 & 55.518 & 673.871 & 32.676 \\
\hline SO4re. Own & & & & & &
\end{tabular}

Source: Own elaboration from Giannoccaro et al. (2010). 